\title{
Stimulation of insulin secretion by large-dose oral arginine administration in healthy adults
}

\author{
ZHU-QI TANG $^{1 *}$, TAO WU ${ }^{2 *}$, SHI-WEI CUI ${ }^{1}$, XIAO-HUI ZHU ${ }^{1}$, TONG YIN ${ }^{1}$, \\ CUI-FANG WANG ${ }^{1}$, JING-YI ZHU ${ }^{1}$ and AI-JUAN WU ${ }^{1}$ \\ ${ }^{1}$ Department of Endocrinology, Affiliated Hospital of Nantong University, Nantong, Jiangsu 226001; \\ ${ }^{2}$ Department of Nephrology, The Second Hospital of Shandong University, Jinan, Shandong 250033, P.R. China
}

Received February 4, 2013; Accepted April 25, 2013

DOI: $10.3892 / \mathrm{etm} .2013 .1119$

\begin{abstract}
The effects of large-dose oral arginine administration on the secretion of insulin by islet $\beta$-cells in healthy adults were determined. Eight non-obese healthy volunteers with normal glucose tolerance participated randomly in tests with four stages (with an interval of at least 3 days): the $300 \mathrm{ml}$ purified water stage (PWS), the $75 \mathrm{~g}$ glucose stage (GSS), the $30 \mathrm{~g}$ arginine stage (ARS) and the $75 \mathrm{~g}$ glucose with $30 \mathrm{~g}$ arginine stage (GAS). Venous blood samples were collected to detect the concentrations of glucose and insulin at baseline (0) and at 15, 30, 45, 60 and $120 \mathrm{~min}$ after drug administration. The glucose and insulin levels were steady in the PWS. The remaining three stages had similarly shaped insulin concentration-time curves, which differed from that of the PWS. The peak concentration of blood insulin and the net incremental area under the curve of blood insulin in the GSS, ARS and GAS were significantly higher compared with those in the PWS ( $\mathrm{P}<0.05)$. In the ARS, the glucose levels remained stable; however, the net incremental area under the curve for blood insulin in the ARS was much lower compared with that in the GSS or GAS $(\mathrm{P}<0.05)$. Large-dose oral arginine administration may slightly stimulate insulin secretion by islet $\beta$-cells in healthy adults with normal glucose tolerance in a manner that is independent of glucose concentration.
\end{abstract}

\section{Introduction}

The main pathogeneses of type 2 diabetes mellitus (T2DM) are insulin resistance and islet $\beta$-cell impairment, and the latter is central to the development and progression of T2DM $(1,2)$. The extent and characteristics of islet $\beta$-cell dysfunction in the different courses of diabetes vary (3). Thus, the accurate evalu-

Correspondence to: Dr Shi-Wei Cui, Department of Endocrinology, Affiliated Hospital of Nantong University, No. 20 Xisi Road, Nantong, Jiangsu 226001, P.R. China

E-mail: zqswen@163.com

${ }^{*}$ Contributed equally

Key words: arginine, insulin, glucose tolerance ation of the insulin secretion level of islet $\beta$-cells in patients is important for the diagnosis, treatment and prognosis judgment of diabetes and for epidemiological analysis. Insulin secretion by islet $\beta$-cells is evaluated using glucose and non-glucose stimulation tests (4). If the islet $\beta$-cell is functionally damaged, then the pancreatic islet does not respond to glucose stimulation but does respond to non-glucose stimulation. If the damage progresses to organic damage, then the pancreatic islet does not respond to any stimulation $(5,6)$.

Arginine is the most commonly used non-glucose stimulus. This amino acid has been widely studied and its intravenous administration has been shown to stimulate insulin secretion by islet $\beta$-cells $(7,8)$. Thus, arginine administration has become a traditional method for the clinical evaluation of the insulin secretion capacity of islet $\beta$-cells $(7,8)$. However, this method promotes insulin secretion non-physiologically since it avoids the effect of gut hormones on insulin secretion. Oral glucose administration stimulates the release of additional insulin compared with intravenous glucose administration in healthy adults (9). Similarly to glucose, arginine stimulates gut-affected insulin secretion through gut loading and promotes greater insulin release through oral rather than intravenous administration. Oral arginine administration may be used clinically in addition to oral glucose administration to evaluate the insulin secretion capacity of the islet $\beta$-cells of patients with T2DM. It may also be used to identify whether islet $\beta$-cell dysfunction or a reduced amount of $\beta$-cells in the pancreas of individuals with hyperglycemia is the cause of the damaged secretory capacity of islet $\beta$-cells, to ensure the appropriate diabetes treatment (10). Gannon et al reported that the serum insulin concentration in nine healthy subjects failed to increase following the oral administration of arginine with an average single dosage of $10.6 \mathrm{~g}$ (11). In a study conducted by Roslyn et al, six obese volunteers with $>5$ years of T2DM were administered oral arginine at $3 \mathrm{~g} / \mathrm{h}$ for $10 \mathrm{~h}$ (total dosage, $30 \mathrm{~g}$ ). The plasma concentrations of C-peptide and insulin over the $10 \mathrm{~h}$ administration period failed to increase (12). An insufficient dosage of arginine may be a reason for the two studies failing to obtain their prospective results (13). However, the stimulatory effect of large-dose oral arginine administration on insulin release remains unknown. In the present study, we investigated the effects of large-dose oral arginine on the secretion of insulin by islet $\beta$-cells in healthy subjects with 
normal glucose tolerance and used large-dose oral glucose administration as the control.

\section{Subjects and methods}

Subjects. Eight non-obese healthy volunteers (four males and four females) aged 20-40 years [mean \pm standard deviation (SD), 30.5 \pm 3.7 years; Table I] with normal body mass indices $\left(\right.$ mean $\pm \mathrm{SD}, 21.0 \pm 2.4 \mathrm{~kg} / \mathrm{m}^{2}$ ) and normal glucose tolerance were enrolled in the study. These subjects took no regular medication and had no family medical history of diabetes. Subjects who suffered with diseases of the digestive system, heart, lung, liver and kidney, or thyroid dysfunction were excluded. Pregnant or lactating subjects and subjects who suffered from stress or infection were also excluded. This study was conducted in accordance with the Declaration of Helsinki and with approval from the Ethics Committee of the Affiliated Hospital of Nantong University. Written informed consent was obtained from all participants.

Measurements. All volunteers participated randomly in tests with four stages (with an interval of at least 3 days): the $300 \mathrm{ml}$ purified water stage (PWS), the $75 \mathrm{~g}$ glucose stage (GSS), the $30 \mathrm{~g}$ arginine stage (ARS) and the $75 \mathrm{~g}$ glucose with $30 \mathrm{~g}$ arginine stage (GAS), respectively. Participants received a low protein diet for 3 days. Afterwards, tests were conducted in a fasting state at 8:00 a.m. Glucose and/or arginine were consumed with $300 \mathrm{ml}$ purified water in $5 \mathrm{~min}$. Venous blood samples were collected from each subject at baseline (0) and at 15, 30, 45, 60 and $120 \mathrm{~min}$ after drug administration to detect the serum concentrations of glucose and insulin. The discomfort reactions of the subjects during the test period and the following 3 days were recorded.

Data analysis. The area under the concentration-time curve (AUC) was calculated by the trapezoidal area formula (13). The net incremental area was AUC minus the area of the fasting plasma glucose or fasting insulin. The relative percentage of the net incremental area was calculated as $\left[\left(\mathrm{AUC}_{\mathrm{N}}-\mathrm{AUC}_{\mathrm{G}}\right) / \mathrm{AUC}_{\mathrm{G}}\right]$ $\mathrm{x} 100$, where $\mathrm{AUC}_{\mathrm{N}}$ represents the $\mathrm{AUC}$ of a certain stage and $\mathrm{AUC}_{\mathrm{G}}$ is the AUC of the GSS.

Statistical analysis. All statistical analyses were performed using SPSS 17.0 for Windows. Data are presented as mean \pm SD for the parameters in Gaussian distribution. Otherwise, the median (quartile) $\left[\mathrm{m}\left(\mathrm{Q}_{\mathrm{L}}, \mathrm{Q}_{\mathrm{U}}\right)\right]$ were used. The serum concentrations of glucose and insulin between different stages were analyzed by repeated measurement variance analysis followed by Tukey's multiple comparison test. The AUCs of the four stages were compared by the rank sum test. $\mathrm{P}<0.05$ was considered to indicate a statistically significant difference.

\section{Results}

Blood glucose concentration. The venous blood samples collected at baseline (0) and at 15, 30, 45, 60 and 120 min after drug administration were used to detect the serum concentration of glucose through the glucose oxidase method. There was no significant difference of blood glucose concentration at baseline ( $0 \mathrm{~min})$ among four stages (Table II; P>0.05).
Table I. Clinical characteristics of the subjects.

Characteristics before test $(n=8)$

\begin{tabular}{lc}
\hline Gender, male $\mathrm{N}(\%)$ & $4(50)$ \\
Age, years & $30.5 \pm 3.7$ \\
Weight, $\mathrm{kg}$ & $56.8 \pm 6.8$ \\
$\mathrm{BMI}, \mathrm{kg} / \mathrm{m}^{2}$ & $21.0 \pm 2.4$ \\
Fasting serum glucose concentration, mmol/1 & $4.8 \pm 0.6$ \\
Fasting insulin concentration, $\mathrm{mIU} / \mathrm{l}$ & $1.79 \pm 1.2$
\end{tabular}

BMI, body mass index. Data are mean \pm standard deviation (SD).

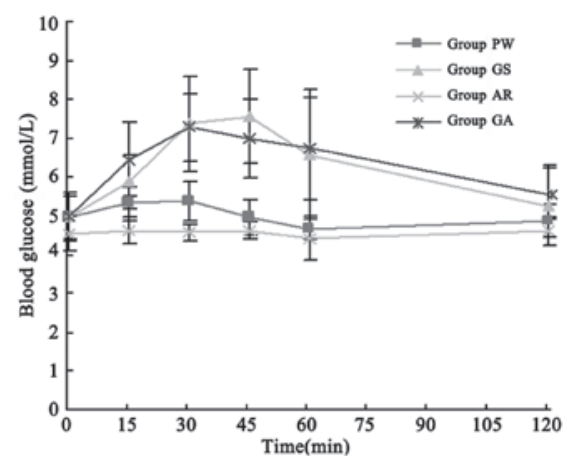

Figure 1. Blood glucose concentration curves of the four stages. Venous blood samples were collected at baseline (0) and at 15,30, 45, 60 and $120 \mathrm{~min}$ after drug administration to detect the serum glucose concentrations by the glucose oxidase method. PW, purified water; GS, glucose; AR, arginine; GA, glucose with arginine.

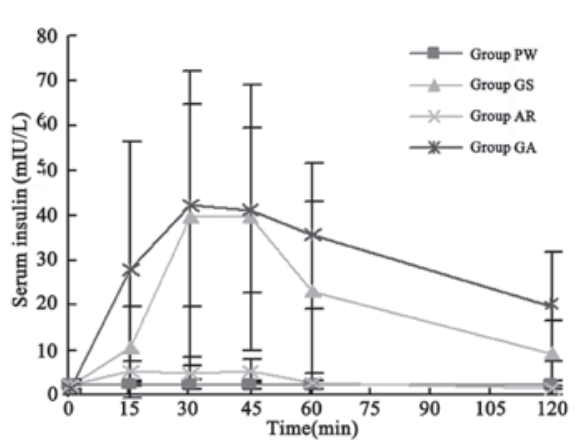

Figure 2. Blood insulin concentration curves of the four stages. Samples collected at baseline (0) and at 15,30,45, 60 and 120 min after drug administration were used to detect the insulin concentrations by a chemoluminescence test. PW, purified water; GS, glucose; AR, arginine; GA, glucose with arginine.

The blood glucose level during the detection period was not reduced significantly in the ARS compared with that in the PWS $(\mathrm{P}>0.05)$. The glucose concentration-time curve of the GSS was similar to that of the GAS (Fig. 1). All samples were run in duplicate.

Blood insulin concentration. The venous blood samples collected were also used to detect the serum concentrations of insulin by a chemoluminescence test and were run in duplicate. At baseline (0 min), no significant difference was identified 
Table II. Blood glucose concentration in the four stages (mmol/l) at different time points.

\begin{tabular}{|c|c|c|c|c|c|c|}
\hline Stage & $0 \mathrm{~min}$ & $15 \mathrm{~min}$ & $30 \mathrm{~min}$ & $45 \min$ & $60 \mathrm{~min}$ & $120 \mathrm{~min}$ \\
\hline PWS & $5.1(4.5,5.5)$ & $5.4(5.0,5.7)$ & $5.4(5.0,5.8)$ & $5.0(4.6,5.3)$ & $4.7(4.4,4.9)$ & $4.9(4.5,5.2)$ \\
\hline GSS & $4.8(4.5,5.4)$ & $6.2(5.3,6.5)^{\mathrm{a}}$ & $7.3(6.4,8.4)^{\mathrm{a}}$ & $7.3(6.5,8.6)^{\mathrm{a}}$ & $6.2(5.2,8.0)^{\mathrm{a}}$ & $5.5(4.4,6.1)$ \\
\hline ARS & $4.6(4.2,4.9)$ & $4.7(4.3,4.9)$ & $4.6(4.4,4.7)$ & $4.7(4.4,4.8)$ & $4.5(3.9,4.9)$ & $4.6(4.3,4.9)$ \\
\hline GAS & $5.0(4.5,5.5)$ & $6.4(5.7,7.2)^{\mathrm{a}}$ & $7.1(6.5,8.0)^{\mathrm{a}}$ & $6.6(6.1,7.8)^{\mathrm{a}}$ & $6.6(5.6,7.8)^{\mathrm{a}}$ & $5.7(5.0,6.1)^{\mathrm{a}}$ \\
\hline
\end{tabular}

Data are presented as median (quartile) $\left[\mathrm{m}\left(\mathrm{Q}_{\mathrm{L}}, \mathrm{Q}_{\mathrm{U}}\right)\right] .{ }^{\mathrm{a}} \mathrm{P}<0.05$ vs. PWS and ARS values. PWS, purified water stage; GSS, glucose stage; ARS, arginine stage; GAS, glucose with arginine stage.

Table III. Serum insulin concentration in the four stages (mIU/l) at different time points.

\begin{tabular}{lcccccc}
\hline Stage & $0 \mathrm{~min}$ & $15 \mathrm{~min}$ & $30 \mathrm{~min}$ & $45 \mathrm{~min}$ & $60 \mathrm{~min}$ & $120 \mathrm{~min}$ \\
\hline PWS & 2.29 & 2.20 & 2.51 & 2.23 & 1.90 & 2.06 \\
& $(1.44,3.13)$ & $(1.68,2.78)$ & $(1.59,3.18)$ & $(1.37,2.97)$ & $(1.46,2.86)$ & $(1.45,2.80)$ \\
GSS & 1.28 & 6.77 & 30.18 & 33.15 & 16.76 & 8.97 \\
& $(0.47,3.22)$ & $(3.08,18.01)$ & $(11.88,66.92)^{\mathrm{b}}$ & $(14.95,64.33)^{\mathrm{b}}$ & $(6.30,39.82)^{\mathrm{b}}$ & $(2.83,15.40)^{\mathrm{b}}$ \\
ARS & 1.91 & 4.89 & 3.60 & 4.15 & 2.11 & $(0.74$ \\
& $(1.20,2.97)$ & $(3.20,7.05)$ & $(1.94,7.60)$ & $(2.89,7.56)^{\mathrm{a}}$ & $(0.49,4.56)$ & $(0.22,2.63)$ \\
GAS & 1.33 & 15.66 & 39.36 & 32.19 & 34.88 & $(21.91,49.11)^{\mathrm{b}}$ \\
& $(0.73,2.12)^{\mathrm{c}}$ & $(3.71,51.74)^{\mathrm{b}}$ & $(23.44,60.95)^{\mathrm{b}}$ & $(25.63,56.57)^{\mathrm{b}}$ & $(9.32,29.90)^{\mathrm{b}}$ \\
\hline
\end{tabular}

Data are presented as median (quartile) $\left[\mathrm{m}\left(\mathrm{Q}_{\mathrm{L}}, \mathrm{Q}_{\mathrm{U}}\right)\right] .{ }^{\mathrm{a}} \mathrm{P}<0.05$ vs. baseline value; ${ }^{\text {b }}<0.05$ vs. ARS value; ${ }^{\mathrm{P}}<0.05$ vs. 120 min value. $\mathrm{PWS}$, purified water stage; GSS, glucose stage; ARS, arginine stage; GAS, glucose with arginine stage.

Table IV. Net incremental area under the concentration-time curve of glucose and insulin and its relative percentage in the four stages.

\begin{tabular}{lcccc}
\hline Stage & $\mathrm{AUC}_{\mathrm{g}}[(\mathrm{mmol} / \mathrm{l}) \times \mathrm{min}]$ & $\mathrm{AUC}_{\mathrm{i}}[(\mathrm{mIU} / \mathrm{l}) \times \mathrm{min}]$ & $\mathrm{AUC}_{\mathrm{g}} / \mathrm{AUC}_{\mathrm{g}}(\%)$ & $\mathrm{AUC}_{\mathrm{i}} / \mathrm{AUC}_{\mathrm{i}}(\%)$ \\
\hline PWS & $-3.5(-61.5,54.6)$ & $-10.7(-66.1,44.8)$ & $-145.0(-136.1,-94.7)$ & $-109.5(-114.3,-87.5)$ \\
GSS & $161.3(42.8,279.8)^{\mathrm{ab}}$ & $2274.1(941.0,3607.3)^{\mathrm{ab}}$ & 100 & 100 \\
ARS & $-1.4(-53.7,50.9)$ & $129.7(-8.1,267.5)^{\mathrm{b}}$ & $-40.5(-123.5,-90.6)$ & $-342.6(-110.7,-80.4)$ \\
GAS & $167.3(91.8,242.7)^{\mathrm{ab}}$ & $3425.2(2502.8,4347.5)^{\mathrm{ab}}$ & $281.0(-2.2,9.7)$ & $227.8(141.6,312.1)$ \\
\hline
\end{tabular}

$\mathrm{AUC}_{\mathrm{g}}$, the net incremental area under the glucose concentration-time curve; $\mathrm{AUC}_{\mathrm{i}}$, the net incremental area under the insulin concentrationtime curve. Data are presented as median (quartile) $\left[\mathrm{m}\left(\mathrm{Q}_{\mathrm{L}}, \mathrm{Q}_{\mathrm{U}}\right)\right] .{ }^{\mathrm{a}} \mathrm{P}<0.05$ vs. ARS value; ${ }^{\mathrm{P}}<0.05$ vs. PWS value. PWS, purified water; GSS, glucose; ARS, arginine; GAS, glucose with arginine.

among four stages (Table III; P>0.05). Insulin concentration in the PWS at each time point after administration demonstrated no significant difference compared with that of the baseline $(\mathrm{P}>0.05)$. However, the peak concentration in the ARS following administration was markedly higher compared with that of the baseline $(\mathrm{P}<0.05)$; however, it was still significantly lower compared with those of the GSS and GAS $(\mathrm{P}<0.05)$. The insulin concentration curves of the GSS, ARS and GAS were all similarly shaped (Fig. 2).

Concentration-time curve. The net incremental AUCs of glucose $\left(\mathrm{AUC}_{\mathrm{g}}\right)$ and insulin $\left(\mathrm{AUC}_{\mathrm{i}}\right)$ in the GSS and GAS increased markedly compared with those of the PWS and ARS
$(\mathrm{P}<0.05) . \mathrm{AUC}_{\mathrm{i}}$ in the ARS increased notably compared with that in the PWS $(\mathrm{P}<0.05)$; however, the difference in $\mathrm{AUC}_{\mathrm{g}}$ between the ARS and PWS was not significant $(\mathrm{P}>0.05)$. In Table IV, the $\mathrm{AUC}_{\mathrm{g}}$ and $\mathrm{AUC}_{\mathrm{i}}$ in the GSS and GAS demonstrated no significant differences $(\mathrm{P}>0.05)$. The $\mathrm{AUC}_{\mathrm{g}}$ and $\mathrm{AUC}_{\mathrm{i}}$ in the GSS and ARS compared with those in the GAS were not significantly different $(\mathrm{z}=-0.42, \mathrm{P}=0.67 ; \mathrm{z}=-1.26$, $\mathrm{P}=0.21$ ).

Tolerability. Arginine tastes bitter, salty and acerbic. Fourteen of the 16 administrations resulted in nausea but not vomiting. Following all 16 administrations, the subjects had diarrhea three to five times without abdominal pain on the day of 
administration and the worst case lasted for seven episodes of diarrhea. All subjects fully recovered on the second day.

\section{Discussion}

A previous study reported that oral protein increases insulin concentration (14). Another study demonstrated that amino acids absorbed by the gut stimulate insulin release and arginine may be the main functional component (15). Floyd et al first identified that intravenous arginine administration increases the insulin concentration in the blood circulation (16). Thus, the intravenous arginine load test is clinically used as the non-glucose promoting secretion test to evaluate the function of islet $\beta$-cells in patients with T2DM (17-20), leading to the exploration of the oral arginine load test.

In 2002, Gannon et al performed the oral arginine load test and identified that oral arginine increases glucagon levels and delays glucose processing without affecting the gastric emptying time. However, this amino acid does not increase the serum insulin concentration (11). Given that the test was conducted on healthy adults and obese volunteers with T2DM by low-dose oral arginine administration, the blood arginine concentration was much lower than the oral sensitivity threshold. In individuals with normal glucose levels, the serum arginine concentration is $0.7 \mathrm{mmol} / 1$ when the insulin secretion volume reaches half of the effective dose $\left(\mathrm{ED}_{50}\right)$ in phase one, and the insulin secretion volume is $2.7 \mathrm{mmol} / \mathrm{l}$ in phase two (13). Therefore, the large-dose oral arginine administration may stimulate insulin secretion as effectively as glucose; this possibility was the motivation for our study.

Previous oral arginine load tests have shown that arginine is perfectly tolerated in all subjects $(11,12)$. However, in the present study, the administration of a large dose of oral arginine resulted in nausea in 14 out of 16 cases and all subjects experienced varying degrees of diarrhea, which indicates that the arginine dose used had reached the maximum tolerance for a single oral dosage. Our results demonstrated that large-dose oral arginine administration has the same effect on glucose concentration as treatment with purified water. Large-dose oral arginine administration stimulates insulin release independent of glucose concentration; however, the extent is much less compared with that of intravenous administration $(8,21)$. The stimulating effect of oral and intravenous glucose on insulin release is not observed in arginine administration (9). This observation may be related to the low bioavailability of $21 \%$ of oral arginine (13). Oral arginine administration is affected by the gastrointestinal digestion absorption rate, arginine metabolism of the intestinal mucosa cells, the firstpass removal rate of the liver and others (22). Intravenous administration avoids the metabolism of the gastrointestinal system and liver, as well as effectively increasing the arginine content in the blood circulation to significantly stimulate islet $\beta$-cells. In addition, oral arginine administration has no stimulating effect on gut-affected insulin secretion the same with oral glucose administration (23). Arginine combined with glucose quickly stimulates insulin secretion and persists for a long time; however, it has no synergistic stimulatory effect $(19,24)$. Promoters of insulin secretion are divided into two classes, namely, the initiator or primary irritant and the enhancer or secondary irritant. The initiator increases insulin release without any other irritant. Glucose is the most effective initiator. The enhancer does not have an effect by itself; however, it promotes insulin secretion with the existence of an initiator, including glucose (25). Arginine may have a stronger stimulatory effect on insulin secretion as a secondary irritant than as a primary irritant. Therefore, oral arginine load tests may be applied in patients with impaired glucose tolerance. A different set of subjects are required for these tests to be conducted. Further studies are required to detect the concentration of serum arginine, glicentin and incretin.

In conclusion, the current study indicates that a large dose of oral arginine does not affect the glucose concentration and is not able to effectively stimulate the insulin secretion of healthy adults with normal glucose tolerance. Further studies are required to determine whether a large dose of oral arginine stimulates insulin secretion in patients with serious sugar toxicity and suffering from impaired glucose tolerance or damaged islet cells that are unresponsive to glucose stimulation. Further improvements, including changing the form of medication, buccal and sublingual administration to avoid the metabolism of the gastro-intestine, or using a microcapsule package technique to reduce the removal rate of the liver, may promote the clinical application of other administration means of arginine stimulation tests as alternatives to intravenous administration.

\section{References}

1. Wajchenberg BL: Beta-cell failure in diabetes and preservation by clinical treatment. Endocr Rev 28: 187-218, 2007.

2. Bonora E: Protection of pancreatic beta-cells: is it feasible? Nutr Metab Cardiovasc Dis 18: 74-83, 2008.

3. Leibowitz G, Kaiser N and Cerasi E: $\beta$-cell failure in type 2 diabetes. J Diabetes Investigation 2: 82-90, 2011.

4. Choi CS, Kim MY, Han K and Lee MS: Assessment of $\beta$-cell function in human patients. Islets 4: 79-83, 2012.

5. Marchetti P, Del Prato S, Lupi R and Del Guerra S: The pancreatic beta-cell in human Type 2 diabetes. Nutr Metab Cardiovasc Dis 16 (Suppl 1): S3-S6, 2006.

6. Del Prato S and Marchetti P: Beta and alpha-cell dysfunction in type 2 diabetes. Horm Metab Res 36: 775-781, 2004.

7. Portha B, Lacraz G, Chavey A, et al: Islet structure and function in the GK rat. Adv Exp Med Biol 654: 479-500, 2010.

8. Emoto M and Nishizawa Y: Acute insulin response to arginine of pancreatic beta-cell. Nihon Rinsho 60 (Suppl 8): 313-318, 2002 (In Japanese).

9. Lindgren O, Carr RD, Deacon CF, et al: Incretin hormone and insulin responses to oral versus intravenous lipid administration in humans. J Clin Endocrinol Metab 96: 2519-2524, 2011.

10. Standl E: The importance of beta-cell management in type 2 diabetes. Int J Clin Pract Suppl 153: 10-19, 2007.

11. Gannon MC, Nuttall JA and Nuttall FQ: Oral arginine does not stimulate an increase in insulin concentration but delays glucose disposal. Am J Clin Nutr 76: 1016-1022, 2002.

12. Chaisanguanthum R and Tayek JA: Oral arginine has no acute effect on blood glucose concentrations or glucose production in type 2 diabetic volunteers. Nutr Res 23: 35-44, 2003.

13. Tangphao O, Grossmann M, Chalon S, Hoffman BB and Blaschke TF: Pharmacokinetics of intravenous and oral L-arginine in normal volunteers. Br J Clin Pharmacol 47: 261-266, 1999.

14. de Oliveira CA, Latorraca MQ, de Mello MA and Carneiro EM: Mechanisms of insulin secretion in malnutrition: modulation by amino acids in rodent models. Amino Acids 40: 1027-1034, 2011.

15. van Loon LJ, Saris WH, Verhagen H and Wagenmakers AJ: Plasma insulin responses after ingestion of different amino acid or protein mixtures with carbohydrate. Am J Clin Nutr 72: 96-105, 2000.

16. Floyd JC Jr, Fajans SS, Conn JW, et al: Stimulation of insulin secretion by amino acids. J Clin Invest 45: 1487-1502, 1966. 
17. Hubert T, Strecker G, Gmyr V, et al: Acute insulin response to arginine in deceased donors predicts the outcome of human islet isolation. Am J Transplant 8: 872-876, 2008.

18. Larsen MO: Beta-cell function and mass in type 2 diabetes. Dan Med Bull 56: 153-164, 2009.

19. Vilsbøll T, Brock B, Perrild H, et al: Liraglutide, a once-daily human GLP-1 analogue, improves pancreatic B-cell function and arginine-stimulated insulin secretion during hyperglycaemia in patients with Type 2 diabetes mellitus. Diabet Med 25: 152-156, 2008.

20. Rickels MR, Naji A and Teff KL: Acute insulin responses to glucose and arginine as predictors of beta-cell secretory capacity in human islet transplantation. Transplantation 84: 1357-1360, 2007.

21. Ma XJ, Jia WP, Zhou J, Lu HJ, Lu JQ and Wu SH: Blood levels of true insulin and immunoreactive insulin in evaluating beta-cell function with arginine stimulation test. Zhejiang Da Xue Xue Bao Yi Xue Ban 35: 255-259, 2006 (In Chinese).
22. Gannon MC and Nuttall FQ: Amino acid ingestion and glucose metabolism - a review. IUBMB Life 62: 660-668, 2010.

23. Nilsson M, Stenberg M,Frid AH,Holst JJ and Björck IM: Glycemia and insulinemia in healthy subjects after lactose-equivalent meals of milk and other food proteins: the role of plasma amino acids and incretins. Am J Clin Nutr 80: 1246-1253, 2004.

24. Eckersten D and Henningsson R: Nitric oxide (NO) - production and regulation of insulin secretion in islets of freely fed and fasted mice. Regul Pept 174: 32-37, 2012.

25. Henquin JC: The dual control of insulin secretion by glucose involves triggering and amplifying pathways in $\beta$-cells. Diabetes Res Clin Pract 93 (Suppl 1): S27-S31, 2011. 